\title{
Solastalgia, place attachment and disruption: insights from a coastal community on the front line
}

\author{
Christopher Phillips ${ }^{1}$ (1) $\cdot$ Conor Murphy ${ }^{1}$
}

Received: 27 April 2020 / Accepted: 12 April 2021 / Published online: 8 May 2021

(C) The Author(s) 2021

\begin{abstract}
We explore how solastalgia, a concept that describes distress and inability to derive solace from one's environment caused by disruptive environmental change, is currently being experienced by a community in southeast Ireland as they struggle to cope with place disruption through loss of a beach by coastal erosion. We analyse relationships between empirical measurements of solastalgia, place attachment and place disruption as well as their association with community outlook for the future. Results indicate that solastalgia, resulting from loss of place, is experienced by almost half of residents, especially those who have lived in the area $>20$ years. Seasonal variation exists for residents who experience the highest levels of solastalgia, with expression strongest in summer. We find that solastalgia is positively correlated with place attachment; those having higher levels of place attachment express stronger feelings of solastalgia and impacts to their lives due to loss of place. Place attachment is most weakly expressed through place dependence, suggesting ongoing adaptation of relationships with place. We find that solastalgia is positively correlated with negative statements regarding future outlook. However, negative outlooks are moderated for those with high levels of place attachment, despite experiencing solastalgia. Given the vulnerability of coastal environments and communities to climate change, understanding and assessing solastalgia will be critical to helping communities navigate environmental disruption.
\end{abstract}

Keywords Solastalgia $\cdot$ Place attachment $\cdot$ Place disruption $\cdot$ Environmental change $\cdot$ Coastal erosion

\section{Introduction}

Loss of place can have profound impacts on individual and community emotional and psychological well-being, sense of identity and ability to cope with further environmental change (Marshall et al. 2019; Adger et al. 2017; Barnett et al. 2016; Fresque-Baxter and Armitage 2012; Connor et al. 2004; Albrecht 2005). Solastalgia is an inability to derive solace from the present state of one's environment (Albrecht 2006; McNamara and Westoby 2011) and describes how personal and community sense of identity, belonging and control is

Communicated by Chandni Singh

Christopher Phillips

Christopher.phillips.2013@mumail.ie

Conor Murphy

Conor.Murphy@mu.ie

1 Irish Climate Analysis and Research UnitS (ICARUS), Department of Geography, Maynooth University, Maynooth, Kildare, Ireland undermined by negative environmental change (Connor et al. 2004; Albrecht 2005; Higginbotham et al. 2006). Solastalgia has been related to a breakdown between an individual's identity and their environment (Askland and Bunn 2018), negative emotional responses that can influence engagement with effective coping responses and paralysis or inaction towards negatively perceived environmental change (Ojala 2013; Ruiz and Hernández 2014; Clayton and Karazsia 2020). Cunsolo and Ellis (2018) show that solastalgia can be expressed following ecological losses, weather extremes and landscape disappearance due to loss of identity and environmental knowledge.

A scoping review of solastalgia by Galway et al. (2019) showed that research has focused on environmental change caused by resource extraction (Connor et al. 2004), climate change (Ellis and Albrecht 2017) and extreme weather events/ natural disasters (e.g. drought, wild fires) (Albrecht et al. 2007; Eisenman et al. 2015). Albrecht (2019) discusses how chronic changes to landscape (e.g. persistent flooding) may have cumulative impacts that gradually erode identity, sense of belonging and lead to distress. With the exception of 
research by Tran et al. (2020), chronic, slowly unfolding degradation caused by coastal erosion as a source of solastalgia has been little studied. Previous research has also tended to focus on landscape icons such as the Great Barrier Reef or economically driven change, such as open cut mining (Marshall et al. 2019; Connor et al. 2004). Overlooked have been more mundane examples, such as coastal degradation and erosion, which may reflect the lived experiences of millions worldwide as they struggle to withstand and cope with place disruption due to coastal erosion, sea level rise and other pressures resulting from climate change. Research also suggests that a gendered experience of solastalgia may be emerging with climate change (McNamara and Westoby 2011). Furthermore, some studies show that solastalgia may lead to concern and uncertainty about the future, stemming from a perceived powerlessness to prevent future losses, thereby exacerbating negative emotions (Galway et al. 2019). However, the role that concern and uncertainty about the future play in how solastalgia is experienced is also under-examined (Galway et al. 2019).

Many scholars have attempted to empirically evaluate solastalgia and confirmed Albrecht's original argument that the concept relates to a deeply held sadness and grief regarding the destruction of valued environments (Higginbotham et al. 2006; Warsini et al. 2014; Eisenman et al. 2015). Connor et al. (2004) detailed the emergence of solastalgia experienced by residents of Upper Hunter Valley in New South Wales, Australia, as a result of open cut mining. Later, Higginbotham et al. (2006) developed an Environmental Distress Scale (EDS) for the Upper Hunter Valley and discovered that unwanted transformation such as open cut mining in valued environments leads to the experience of solastalgia. Similarly, Warsini et al. (2014) used a modified Environmental Distress Scale in Indonesia (IEDS) to examine solastalgia following natural disasters. These studies have found that place attachment may be an important mediating factor in the experience of solastalgia. Although there is a significant history of research on place attachment and disruption, there have been calls for enhanced understanding of the relationship between place attachment and solastalgia in different contexts (Cunsolo and Ellis 2018; Galway et al. 2019).

Place attachment has been explored by scholars in many different disciplines such as geography (Von Wirth et al. 2016), environment psychology (Clarke et al. 2018) and sociology (McKnight et al. 2017). These disciplines have arrived at various definitions, measures and models (Greer et al. 2020). A common description of place attachment is a positive emotional connection to places or landscapes that often inspires individuals and communities to engage in place protective actions when the place they are attached to comes under threat (Lewicka 2011; Devine-Wright 2013). Place attachment can be explained through examining the connections or emotional bonds that individuals and communities form with an environment (Clarke et al. 2018). Strength of place attachment has been shown to vary with age, length of residence and homeownership (Lewicka 2011). People assign meaning to places they are familiar with and subsequently form intimate bonds and feelings of belonging towards that place (Hess et al. 2008). It is commonly argued that how people identify with a place is an important aspect of place attachment as well as their sense of personal and social self (Greer et al. 2020; Lewicka 2011; Twigger-Ross and Uzzell 1996).

Many scholars consider place attachment as having two related dimensions: place identity and place dependence (Clarke et al. 2018; Anton and Lawrence 2016a; Moore and Graefe 1994). Place dependence can be thought of as a resource/materially driven relationship, described as the functional bonds people form with a place (Moore and Graefe 1994; Greer et al. 2020). It is often determined by how well a place can facilitate people's goals, desired activities such as recreational, occupational or social activities, and physical characteristics such as public transport or natural resources (Stokols and Shumaker 1987; Williams and Vaske 2003; Quinn et al. 2015, Greer et al. 2020). For place dependence to develop and be maintained, a place must meet a person's needs, be functionally desirable and provide the capacity to fulfil a person's goals better than any other place (Anton and Lawrence 2016a; Greer et al. 2020; Lemée et al. 2019).

Place identity is the symbolic, emotional and social links to a place which are intertwined with the ability to maintain a sense of self in one's environment (Devine-Wright 2013; Lemée et al. 2019; Korpela 1989). An individual's sense of place identity represents their emotions, values, memories, attitudes and behaviour related to the environment in which they live, which defines their daily experiences (Proshansky et al. 1983). Place identity develops through personal experiences and interactions within a geographical setting over time and is a complex process where an individual or community becomes psychologically invested in a place and acquires a sense of belonging (Lewicka 2011; Anton and Lawrence 2016a; Lemée et al. 2019; Proshansky et al. 1983). Strong emotional bonds to place are often formed when that place is perceived to positively benefit identity and satisfy social, psychological, cultural and biological needs (Lemée et al. 2019; Belanche et al. 2017; Proshansky et al. 1983). Identity is important for withstanding place change (Fresque-Baxter and Armitage 2012). Impacts to self-identity from environmental degradation can lower an individual's ability to cope with further place changes (Fresque-Baxter and Armitage 2012).

Place disruption is experienced when a place is modified, degraded or destroyed and is often associated with negative emotions and grief (Cheng and Chou 2015). Relocation, forced migration or physical changes can lead to the 
disruption of place attachment (Cheng and Chou 2015; Devine-Wright and Howes 2010; Fried 2000). The size and speed of change can also result in different responses and adaptive actions (Devine-Wright 2013). Incremental changes can potentially be dealt with by adjusting or adapting; however, more sudden and/or dramatic changes can result in greater disruption of material and psychological bonds. Disruption of such connections can arise following displacement, loss of traditional culture, loss of place through environmental transformations, losses to sense of identity and belonging and can often result in mental health challenges as a threat to the environment is understood as a threat to self (Fullilove 1996; Devine-Wright 2009). Such place changes, including proposed or anticipated changes, are more likely to be viewed as negative and seen as threatening by those who have stronger place attachment (Marshall et al. 2019; Anton and Lawrence 2016b; Devine-Wright 2013).

Using the gradual disappearance of a beach in Ireland as a case study, we examine the relationships between impacts of slow and ongoing environmental loss on the experience of solastalgia in a coastal community. Using questionnaire surveys, we investigate the inter-relationships between solastalgia, place attachment and place disruption and their relationship with community outlook for the future as a result of coastal erosion. In particular, we examine: (i) the extent to which the community experiences solastalgia as a result of place disruption, (ii). the relationship between place attachment and feelings of solastalgia, and (iii) the association between solastalgia, place attachment and resident's future outlook.

\section{Methods}

\section{Case study}

Courtown Harbour-Riverchapel is located in County Wexford in the southeast of Ireland, $6 \mathrm{~km}$ east of Gorey, County Wexford and $16 \mathrm{~km}$ south of Arklow, County Wicklow (WCC 2014a, b). Courtown originated as a fishing village, and the harbour was built in 1825 to aid fishermen launching their boats (WCC 2014a, b). Courtown began to thrive as a tourist destination in the 1860s following the construction of a railway, allowing tourists to travel from Dublin and the Midlands Region. Tourism has continued to be the main economic activity and is considered by the Wexford County Council to hold the greatest potential to increase economic growth and employment in the area (WCC 2014a). Tourism assets are focused around the harbour and natural amenities, including a blue flag beach and extensive woodlands and coastal walks (WCC 2014a, b). There are many established and permanent residential sites in the area, as well as holiday homes and caravan parks, which serve temporary residents (WCC 2014a, b).

Courtown and Riverchapel were once separate villages, and up until the 1990s development of Riverchapel was slow, but residential development rapidly increased following the introduction by the national government of the "Renewal Scheme for Traditional Seaside Resorts" in 1995 (WCC 2014a). The population of Courtown Harbour-Riverchapel has expanded rapidly; in 2006, the population was 1421, increasing to 2857 in 2011 (CSO 2011; WCC 2014a, b). In 2016, the census covered Courtown Harbour-Riverchapel and nearby Ardamine as a single settlement with a population of 3591 (CSO 2016). Unemployment rates are high $(26.2 \%)$ and above the average for County Wexford (16.6\%) (WCC 2018).

In recent decades, the area has been badly affected by coastal erosion. Winter storms have heavily impacted the soft coastline. In particular, the main beach in Courtown (the North beach) has been impacted and undergone extensive coastal protection works through the installation of rock armour, which has drastically transformed the area (WCC 2014a, b) (see Fig. 1). Rather than the expansive beach of previous years, the North beach is now very narrow with rock armour covering most of the area and extending for around $750 \mathrm{~m}$. Moreover, additional stretches of coastline extending from Ardamine to the North beach in Courtown have been deemed to be at a significant risk of future coastal erosion. Local property owners have taken some action to delay the coastal erosion by placing rock armour along the sea bank (WCC 2014a, b). A Beach Nourishment and Marina Project was drafted over a decade ago, but progress on this project has been slow (Gorey Guardian 2019). Engineers were appointed in 2016 by the Wexford County Council to develop the scheme including coastal protection, and a separate plan for the transport of replenishing sand was drafted. Public consultation of the 'Courtown North Beach and Marina Feasibility Study' took place on $12^{\text {th }}$ November 2019 and remained on view until $11^{\text {th }}$ December 2019 (WCC 2019). However, local councillors have indicated that significant funding is needed from the central government (Gorey Guardian 2019). Local residents are anxious to see the project begin which is unlikely to start for a number of years as it still awaits approval (Gorey Guardian 2019). Presently, the Wexford County Council plans to maintain current coastal defences but also to erect breakwaters to further protect and attempt to replenish the beaches (WCC 2014b).

\section{Participants and sample method}

We developed a questionnaire survey containing empirical measurements of solastalgia, place attachment, perceptions of place disruption and outlooks for the future of Courtown and Riverchapel. Piloting was conducted with 15 inhabitants of Courtown in November 2018. A week was spent in 
Fig. 1 Left: North beach at Courtown 1967. Right: North beach at Courtown 2015, including rock armour. Sources: Doyle, E. (1967). TIFF file; Comerford, P. (2015). TIFF file
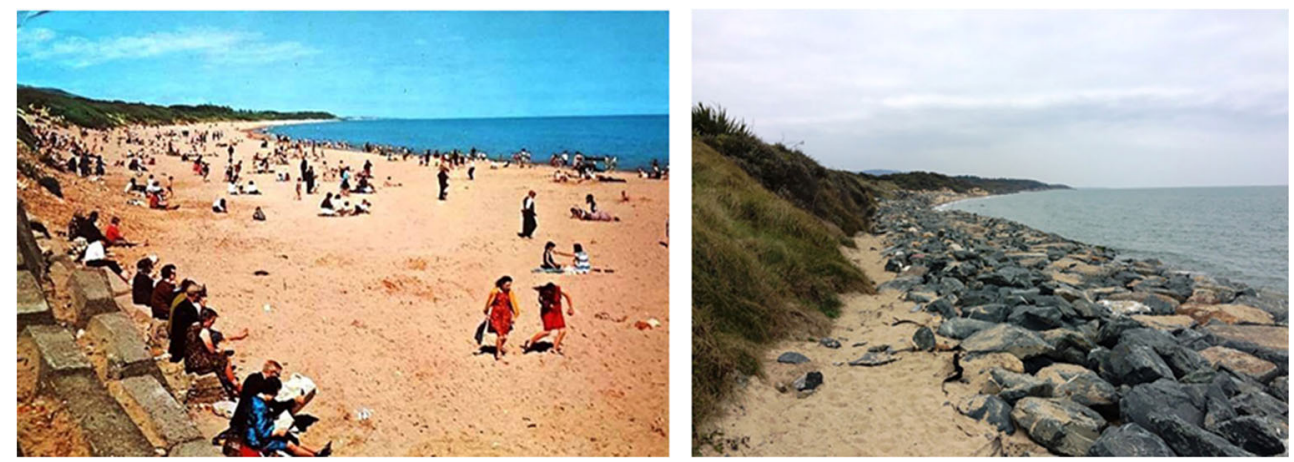

Courtown harbour and Riverchapel talking and listening to locals which included some participants from the pilot questionnaire, in unstructured and casual conversations. We conducted this work to help us understand their use of language when describing changes to the beach. The word 'loss' was repeatedly used by local residents to describe these changes, which informed the language used during question design for piloting. Discussions with residents also informed us that residents from Riverchapel should be included, as many would have moved from Courtown to the neighbouring area of Riverchapel. Piloting allowed us to refine how questions were asked, survey presentation and length, sampling strategy and delivery method.

Following piloting and refinement, we distributed the questionnaire survey to randomly selected households in Courtown and Riverchapel over two field campaigns: in January 2019 (winter sample) and July 2019 (summer sample). Consent for participation was obtained through the inclusion of an information letter and consent form attached to the front of the questionnaire. Questionaries were used only if consent had been provided. The inclusion of two campaigns allowed us to sample residents of the same community twice to investigate if there are seasonal differences in key concepts tested. Surveying was undertaken using a drop and collect method similar to Allred and Ross-Davis (2011) and Clarke et al. (2018) whereby questionnaires were delivered 1 day and collected the next. Census data indicates that the population of Courtown Harbour-Riverchapel and Ardamine was 3591 in 2016 (CSO 2016). Disregarding residents of this settlement under the age of 18 leaves a viable population of 2561 . The number of permanent private households within the settlement of Courtown Harbour-Riverchapel and Ardamine on the night of the census was 1348. Using postcodes for the area, we sampled every third household from randomly selected streets/estates within the confines of the study area for the first field campaign in January, similar to the sampling strategy employed by Clarke et al. (2018). We sampled every first household from the previously selected three during the second field campaign in July in order to sample the same community twice. A total of 800 questionnaires were delivered, one questionnaire was distributed per household, with responses sought from one adult. There was no overlap in households sampled between winter and summer campaigns. Sampling with no overlap over two field campaigns within the same community/area ensured we obtained meaningful results about that particular community's views while also limiting participant fatigue and biased responses. We collected 271 surveys in total (99 winter plus 172 summer surveys), with an overall response rate of $33.9 \%$.

\section{Measures and analytical procedures}

Survey items were designed to elicit empirical measurements of solastalgia, place attachment, place disruption and resident's outlook for the future. In all cases, items were measured using a 5-point Likert scale ranging from $1=$ strongly agree to $5=$ strongly disagree, with $3=$ neither agree nor disagree. Where an individual response was missing, pairwise deletion was performed (Pallant 2013; Clarke et al. 2018). Nonparametric statistical tests are used throughout due to data being non-normally distributed. The Mann-Kendal $U$ test was employed to discern differences between groups, including gender, seasonal differences and residents impacted and not impacted by the loss of the beach. The Kruskal-Wallis test was used to discern differences between age groups, length of residence and place attachment levels. Spearman's correlations were calculated to ascertain the relationships between solastalgia, place attachment and outlook for the future (Pallant 2013).

\section{Solastalgia scale}

An analysis of the literature on solastalgia indicated which items are most reliable to construct a single uni-dimensional scale to measure solastalgia. In particular, we draw on statements from Higginbotham et al. (2006) who developed and validated an environmental distress scale, which includes items measuring solastalgia. Our single uni-dimensional scale was constructed to measure solastalgia by combining seven relevant items adapted from the Higginbotham et al. (2006) scale 'Feelings of Solastalgia from Environmental Change', tailored to local context. The items measure emotions which 
are considered by Higginbotham et al. (2006) to relate to solastalgia as a result of environmental change, including; sadness 'I feel saddened by the loss of the beach at Courtown'; worry 'I am worried that the valued aspects of Courtown are being lost'; shame/disappointment 'I feel disappointed in the way Courtown looks now'; belonging undermined 'My sense of belonging to this place has been undermined by the loss of the beach'; nostalgia 'Sometimes I find myself thinking about times when the beach was larger', 'I feel that the beach suited my way of life more in the past' and; unique environmental aspects lost 'I am upset over the loss of the beach because it is part of my heritage' (see Table 2). A Cronbach Alpha test was carried out on these seven statements which demonstrated good internal reliability $(\alpha=0.85)$. High Cronbach alpha values were also returned for individual items within the scale, indicating that internal validity of our solastalgia scale is satisfactory. We split the sample into three equal groups representing high, medium and low levels of solastalgia according to the method Kaltenborn and Bjerke (2002) applied to their place attachment scale. We extracted the mean solastalgia score of each group to assess differences between groups.

\section{Place disruption}

We asked one yes/no question 'is your life impacted by the loss of the beach' to determine if place disruption has impacted residents' lives. This was accompanied by two open-ended questions encouraging respondents to detail how their life has been impacted and if their feelings towards Courtown have changed. We used a thematic analysis to identify the most common impacts and feelings as a result of disruption and include relevant quotes. To determine differences in solastalgia and place attachment experienced by those who are impacted by loss of the beach and those who are not, we conducted Mann-Whitney $U$ statistical tests using the entire dataset (i.e. winter and summer samples). To investigate how people with different levels of place attachment are impacted by loss of the beach, we conducted a Kruskal-Wallis statistical test using the impacted group data.

\section{Place attachment scale}

Drawing on previous research that attempts to empirically quantify place attachment, we employed items related to place identity and place dependence, tailored to the specific context of this study, to measure place attachment (e.g. Clarke et al. 2018; Kaltenborn and Bjerke 2002). A 3-item scale was employed to measure place identity consisting of the statements 'I have good memories of Courtown beach', 'I feel part of the community in Courtown', 'Courtown beach is part of my identity' (Clarke et al. 2018; Kaltenborn and Bjerke 2002) (see Table 2). A 3-item scale was also used to measure place dependence consisting of the statements 'Development of the area is important to me', 'No other place can compare to Courtown beach' and 'I get more satisfaction out of visiting Courtown beach than any other' also tailored from Clarke et al. (2018) and Kaltenborn and Bjerke (2002) (see Table 2). Finally, a single uni-dimensional scale was constructed to measure place attachment by combining all six items. A Cronbach alpha test confirmed the place attachment scale to have good internal reliability $(\alpha=0.80)$ (Von Wirth et al. 2016). High Cronbach alpha scores were also returned for individual items within the scale, indicating that internal validity is satisfactory. We split the sample into three equal groups representing high, medium and low levels of place attachment according to the method employed by Kaltenborn and Bjerke (2002). We extracted the mean place attachment score of each group to assess differences between groups.

\section{Outlook for the future}

We use the term 'future outlook' to encapsulate viewpoints associated with concerns for the future. Three 5-point Likert statements were used consisting of 'I am concerned that future generations will not be able to enjoy the natural environment at Courtown', 'There is not much of a future for me in Courtown' and 'I feel that Courtown has a positive future'. The relationship between these statements and the constructed scales for solastalgia and place attachment was used to determine if loss of place due to environmental change and resultant experiences of solastalgia impacted an individual's outlook for the future.

\section{Results}

\section{Socio-demographics}

Socio-demographics on age, length of residence and gender were collected. The questionnaire was distributed to adults only. The largest age groups in the sample are 35-44 (25.1\%) and 45-54 (18\%). The smallest groups are 18-24 year olds $(5.3 \%)$ and $75+(7.7 \%)$. The majority of participants in the survey have lived within Courtown Harbour and Riverchapel for over 11 years $(56.6 \%)$, and $3.3 \%$ of respondents have lived there less than a year. A gender bias exists within our sample relative to the 2016 census data (see Table 1), with the proportion of females $(56.5 \%)$ within the survey sample significantly greater than in the census and the proportion of males $(36.6 \%)$ significantly lower $(p<0.05)$. No other statistically significant biases in our sample, relative to census data, were found. 
Table 1 Socio-demographic statistics (age, gender and length of residence) displayed as percentages and compared to the Census 2016 data for Courtown/ Riverchapel/Ardamine (Central Statistics Office 2016)

\begin{tabular}{|c|c|c|c|}
\hline \multicolumn{2}{|l|}{ Demographic factors } & \multirow{2}{*}{$\begin{array}{l}\begin{array}{l}\text { Courtown/Riverchapel } \\
\text { survey }\end{array} \\
8.5\end{array}$} & \multirow{2}{*}{$\begin{array}{l}\text { Census data (Courtown } \\
\text { Riverchapel/Ardamine) }\end{array}$} \\
\hline Age $(\%)$ & $18-24$ & & \\
\hline & $25-34$ & 16.9 & 13.2 \\
\hline & $35-44$ & 25.1 & 21.5 \\
\hline & $45-54$ & 18.0 & 21.1 \\
\hline & $55-64$ & 14.4 & 15.5 \\
\hline & $65-74$ & 10.2 & 13.6 \\
\hline & $75+$ & 6.8 & 7.5 \\
\hline \multirow[t]{4}{*}{ Gender $(\%)$} & Male & $36.6 * *$ & 47.5 \\
\hline & Female & $58.5^{*}$ & 52.5 \\
\hline & Prefer not to disclose & 1.9 & \\
\hline & NA & 3.0 & \\
\hline \multirow[t]{5}{*}{ Length of residence $(\%)$} & $\begin{array}{l}<1 \text { year } \\
1-5 \text { years }\end{array}$ & $\begin{array}{r}3.3 \\
18.1\end{array}$ & \\
\hline & $6-10$ years & 18.5 & \\
\hline & $11-15$ years & 26.6 & \\
\hline & $16-20$ years & 11.8 & \\
\hline & $20+$ years & 17.7 & \\
\hline
\end{tabular}

\section{The extent to which the community experiences solastalgia}

Respondents for the entire (i.e. winter and summer) sample reported a mean $(M)$ score of 2.12 (standard deviation $(\mathrm{SD})=$ 0.82), equivalent to agree on the 5-point Likert scale adopted, for the uni-dimensional solastalgia scale (see Table 2). We split the sample into three groups representing high $(M=1.28)$, me$\operatorname{dium}(M=2.02)$ and low $(M=3.04)$ levels of solastalgia. Both high and medium groups tend towards strongly agree and agree for the uni-dimensional scale, respectively, indicating the strength of feelings of solastalgia, whereas the low group tend towards 'neither agree nor disagree' (see Table 2). The only one of the seven solastalgia items within the scale not to tend towards agree or strongly agree is ' $m y$ sense of belonging to this place has been undermined by the loss of the beach' $(M=3.00, \mathrm{SD}=1.18)$. The items 'I feel saddened by the loss of the beach at Courtown' $(M=1.52, \mathrm{SD}=0.84)$, 'I am worried that valued aspects of Courtown are being lost' $(M=1.72, \mathrm{SD}=.95)$ and 'I am disappointed in how Courtown looks now as a result of losing the beach' $(M=1.71, \mathrm{SD}=.98)$ show the strongest reported scores. There is a sense of nostalgia as many respondents reported that the beach suited their way of life better in the past $(M=2.27$, SD $=1.21$ ), with most agreeing with the statement 'Sometimes I find myself thinking about times when the beach was larger' $(M=$ 2.03, $\mathrm{SD}=1.12$ ).

Kruskal-Wallis tests show that there are no statistically significant differences in the strength of solastalgia between various age groups for the single uni-dimensional solastalgia scale. However, statistically significant differences do exist between age groups for the scale items 'I am disappointed in how Courtown looks now as a result of losing the beach' ( $H=$ $17.347, p<.01)$ and 'I am worried that valued aspects of Courtown are being lost' $(H=18.072, p<.01)$ with the 55 64 (mean ranks $=100.11,98.11)$ and $65-74$ (mean rank $=$ $114.50,107.47)$ age groups having the strongest feelings. No statistically significant differences were found for other scale items (see Table 3). Statistically significant differences were found between length of residence and strength of solastalgia $(H=30.294, p<.01)$ for the solastalgia scale, with the highest mean rank being 74.70 for $20+$ years group (see Table 3). Every scale item besides 'my sense of belonging to this place has been undermined by the loss of the beach' $(H=$ 5.014, $p=0.414$ ) showed similar statistically significant differences (see Table 3). Results indicate that those who have lived in the area for a longer period of time experience stronger feelings of solastalgia. We find no significant difference in our solastalgia scale by gender or season (winter/summer).

To investigate further, we split the sample into three groups representing high, medium and low levels of solastalgia and conducted Mann-Whitney $U$ tests with gender and season to determine differences between solastalgia groups by level. No statistically significant differences were found for high, medium or low-level groups for gender or medium and low groups for seasons. However, there are statistically significant differences within the high solastalgia group between seasons ( $U=$ $687.00, p=.05$ ) showing stronger solastalgia in the summer with a mean rank of 41.06 and 52.02 for winter. 
Table 2 Descriptive statistics and Cronbach alpha reliability scores for place attachment and solastalgia. Also shown are the six scale items for place attachment and seven scale items for solastalgia, statements concerning future outlook, place attachment and solastalgia by level. The 5-point Likert scale responses range from $1=$ Strongly agree, $2=$ Agree, $3=$ Neither agree nor disagree, $4=$ Disagree, $5=$ Strongly disagree

\begin{tabular}{|c|c|c|c|c|c|}
\hline Scales and items & $\begin{array}{l}\text { High } \\
\text { Low }\end{array}$ & Medium & $\begin{array}{l}\text { Cronbach's } \\
\text { alpha }\end{array}$ & $\begin{array}{l}\text { Mean } \\
(M)\end{array}$ & $\begin{array}{l}\text { Std. deviation } \\
(S D)\end{array}$ \\
\hline Place attachment (One single composite item) $n=265$ & \multirow[t]{7}{*}{1.55} & \multirow[t]{7}{*}{$2.26 \quad 3.15$} & .77 & 2.32 & .74 \\
\hline I have good memories of Courtown beach & & & .77 & 1.63 & .92 \\
\hline I feel part of the community in Courtown & & & .74 & 2.05 & 1.00 \\
\hline Courtown beach is part of my identity & & & .72 & 2.89 & 1.20 \\
\hline Development of the area is important to me & & & .77 & 1.39 & .58 \\
\hline No other place can compare to Courtown beach & & & .70 & 3.06 & 1.23 \\
\hline I get more satisfaction out of visiting Courtown beach than any other & & & .71 & 2.97 & 1.24 \\
\hline Solastalgia (One composite item) $n=265$ & \multirow[t]{12}{*}{1.28} & \multirow[t]{12}{*}{2.023 .04} & .87 & 2.12 & .82 \\
\hline I feel saddened by the loss of the beach at Courtown & & & .86 & 1.52 & .84 \\
\hline I feel disappointed in the way Courtown looks now & & & .86 & 1.71 & .98 \\
\hline I am worried that the valued aspects of Courtown are being lost & & & .85 & 1.72 & .95 \\
\hline My sense of belonging to this place has been undermined by the loss of the beach & & & .86 & 3.00 & 1.18 \\
\hline Sometimes I find myself thinking about times when the beach was larger & & & .85 & 2.00 & 1.10 \\
\hline I feel that the beach suited my way of life more in the past & & & .84 & 2.27 & 1.21 \\
\hline I am upset over the loss of the beach because it is part of my heritage & & & .86 & 2.58 & 1.22 \\
\hline Future outlook single Likert statements & & & & & \\
\hline $\begin{array}{l}\text { I am concerned that future generations will not be able to enjoy the natural environment } \\
\text { at Courtown }\end{array}$ & & & & 1.52 & .77 \\
\hline There is not much of a future for me in Courtown & & & & 3.34 & 1.22 \\
\hline I feel that Courtown has a positive future & & & & 2.51 & 1.09 \\
\hline
\end{tabular}

\section{Life impacted and solastalgia}

The results show that $42.7 \%$ of residents in the entire sample responded yes to the question 'Is your life impacted by the loss of the beach?'. We analysed the sub-sample of respondents that indicated their lives have been impacted to ascertain the extent of disruption that they are experiencing as well as the open-ended responses indicating the reasons residents' lives have been impacted. All responses detailed negative impacts. The most common impacts reported by loss of the beach include recreational activities (walking and swimming), meeting family, view/aesthetics (beach and town), community, tourism, memories and therapeutic opportunities. Residents who reported reasons for why their lives have been impacted said the following (See supplementary material for all responses):

Recreation: 'It was a beach and I enjoyed swimming and was easily accessible for family. I would sea swim most of the year. I've stopped using the beach altogether now and swim somewhere else. No longer are a place I will frequent....'

Meeting family: 'Less time spent with family and friends at the beach means I see them less. Main meeting point was the beach'.
View/aesthetics: 'A feeling that such natural beauty has been lost and a strong reminder of climate change and the rate that change is happening'.

Community: 'Courtown in the 1950s was not just a seaside resort. But a place to meet and communicate with friends old and new. Such meetings were the highlight of the week and looked forward to with great anticipation. Of course many of the people involved were from local surrounding areas but not solely. There was also a fair sprinkling of visitors'. 'The beach was the focal point of the community. Now that is lost'.

Tourism: 'Courtown was once a thriving holiday destination and now due to loss of the beach businesses have closed and been left to rot and local people have lost their jobs. There are so many things that can be done by the government to bring the beach back. It really is a shame'.

Memories: 'Saddened as have fond memories of my dad walking on the beach. My dad is no longer here and neither is the beach'.

Therapeutic opportunities: 'The beach was where I liked to go when I feel stressed, the waves coming and going'.

The Mann-Whitney $U$ test indicated that people who selfreported that their lives are impacted by loss of the beach 
Table 3 Kruskal-Wallis $H$ statistics between solastalgia (one composite item and scale items, see Table 2), place attachment (one composite item and scale items, see Table 2), age and length of residence. $H$ is the test statistic used

\begin{tabular}{|c|c|c|c|c|c|c|}
\hline Kruskal-Wallis $H$ & $\begin{array}{l}\text { Place attachment level } \\
\text { (H) }\end{array}$ & $\begin{array}{l}p \\
\text { value }\end{array}$ & $\begin{array}{l}\text { Age } \\
(H)\end{array}$ & $\begin{array}{l}p \\
\text { value }\end{array}$ & $\begin{array}{l}\text { Length of residence } \\
\text { (H) }\end{array}$ & $\begin{array}{l}p \\
\text { value }\end{array}$ \\
\hline Solastalgia & 64.49 & $<.01$ & 12.02 & .41 & 30.29 & $<.01$ \\
\hline I feel saddened by the loss of the beach at Courtown & 33.13 & $<.01$ & 11.86 & .07 & 15.11 & .01 \\
\hline I feel disappointed in the way Courtown looks now & 12.38 & $<.01$ & 17.35 & .01 & 22.82 & $<.01$ \\
\hline I am worried that the valued aspects of Courtown are being lost & 29.74 & $<.01$ & 18.07 & .01 & 18.16 & $<.01$ \\
\hline $\begin{array}{l}\text { My sense of belonging to this place has been undermined by the loss of } \\
\text { the beach. }\end{array}$ & 49.13 & $<.01$ & 3.67 & .72 & 5.01 & .41 \\
\hline $\begin{array}{l}\text { Sometimes I find myself thinking about times when the beach was } \\
\text { larger }\end{array}$ & 35.23 & $<.01$ & 11.33 & .08 & 30.19 & $<.01$ \\
\hline I feel that the beach suited my way of life more in the past & 35.64 & $<.01$ & 8.90 & .18 & 17.21 & $<.01$ \\
\hline I am upset over the loss of the beach because it is part of my heritage & 70.76 & $<.01$ & 4.77 & .87 & 38.86 & $<.01$ \\
\hline Place attachment & & & 11.48 & .07 & 23.09 & $<.01$ \\
\hline I have good memories of Courtown beach & & & 7.22 & .30 & 34.17 & $<.01$ \\
\hline I feel part of the community in Courtown & & & 5.89 & .47 & 16.78 & $<.01$ \\
\hline Courtown beach is part of my identity & & & 5.33 & .50 & 30.77 & $<.01$ \\
\hline Development of the area is important to me & & & 6.14 & .41 & 14.28 & .01 \\
\hline No other place can compare to Courtown beach & & & 12.03 & .06 & 5.19 & .39 \\
\hline I get more satisfaction out of visiting Courtown beach than any other & & & 17.04 & .01 & 3.15 & .68 \\
\hline
\end{tabular}

experience solastalgia significantly stronger than those who $\operatorname{did}$ not $(U=3889.00, p<0.01)$, with a mean rank of 90.19 for those impacted and 150.80 for those not impacted (see Table 4). Similar statistically significant differences exist for each item within the solastalgia scale (see Table 4 and Fig. 2a). There are also statistically significant differences between groups representing high $(U=573.00, p=.04)$ and low $(U=$ $405.50, p<.01)$ levels of solastalgia for life impacted, with those experiencing high levels of solastalgia more likely to answer that their lives had been impacted by loss of the beach.

\section{Place attachment and relationship with solastalgia}

Respondents for the entire sample reported a mean score of 2.32 ( $\mathrm{SD}=0.74)$, tending towards agree on the 5-point Likert scale adopted, for the uni-dimensional place attachment scale (Table 2). Most items within the place attachment scale also tend towards agree, except for 'No other place can compare to Courtown beach' $(M=3.06, \mathrm{SD}=1.23)$ and 'I get more satisfaction out of visiting Courtown beach than any other' $(M=2.97, \mathrm{SD}=1.24)$; however, we note the large standard deviations in these responses (Table 2). Both statements comprise the place dependence aspect of place attachment, which indicates that place dependence is low. Place identity statements tend towards agree, the weakest being 'Courtown beach is part of my identity' $(M=2.89, \mathrm{SD}=1.20)$, which also has a large standard deviation (Table 2).

Place attachment is significantly positively correlated with length of residence (rho $=0.19, n=269, p<0.01$ ), but not with age (see Table 5). Kruskal-Wallis tests showed statistically significant differences between length of residence and strength of place attachment $(H=23.09, p \leq .01)$ with the highest mean rank being 75.66 for the $20+$ years group (see Table 3). Every scale item except for 'No other place can compare to Courtown beach' $(H=5.186, p=.39)$ and 'I get more satisfaction out of visiting Courtown beach than any other' $(H=3.148, p=.68)$ showed similar statistically significant differences by length of residence (see Table 3). There were no statistically significant differences between age groups and strength of place attachment for the uni-dimensional scale.

The Mann-Whitney $U$ test indicated that people whose lives have been impacted by the loss of the beach had significantly stronger place attachment than those who have not been impacted by loss of the beach $(U=3889.00, p<.01)$, with a mean rank of 92.86 for those impacted and 139.48 for those not impacted (see Table 4). Similar statistically significant differences were found for each item within the place attachment scale (see Table 4 and Fig. 2b). No statistically significant differences were found between winter and summer samples for the place attachment scale or scale items. There were also no statistically significant differences between gender and strength of place attachment. However, males are statistically significantly more likely to agree with the item 'Development of the area is important to me' $(U=$ $5665.50, p=.04$ ) with a mean rank of 109.12 for males and 124.73 for females (Table 4).

We find a significant positive correlation between solastalgia and place attachment (rho $=0.49, n=268, p<$ 0.01) (Table 5). To investigate further, we split the sample 
Table 4 Mann-Whitney $U$ statistics between solastalgia (one composite item and scale items, see Table 2), place attachment (one composite item and scale items, see Table 2), life impacted (yes/no), gender (male/female) and season (winter/ summer). $U$ is the test statistic used

\begin{tabular}{|c|c|c|c|c|c|c|}
\hline Mann-Whitney $U$ & $\begin{array}{l}\text { Life impacted } \\
\text { (U) }\end{array}$ & $\begin{array}{l}p \\
\text { value }\end{array}$ & $\begin{array}{l}\text { Gender } \\
(U)\end{array}$ & $\begin{array}{l}p \\
\text { value }\end{array}$ & $\begin{array}{l}\text { Season } \\
(U)\end{array}$ & $\begin{array}{l}p \\
\text { value }\end{array}$ \\
\hline Solastalgia & 4836.00 & $<.01$ & 6765.00 & .41 & 7390.50 & .41 \\
\hline I feel saddened by the loss of the beach at Courtown & 3889.00 & $<.01$ & 7105.00 & .85 & 7753.00 & .86 \\
\hline I feel disappointed in the way Courtown looks now & 5183.50 & $<.01$ & 6968.50 & .61 & 7832.50 & .96 \\
\hline I am worried that the valued aspects of Courtown are being lost & 6049.00 & $<.01$ & 7049.50 & .75 & 7488.50 & .48 \\
\hline $\begin{array}{l}\text { My sense of belonging to this place has been undermined by the loss of the } \\
\text { beach. }\end{array}$ & 5170.50 & $<.01$ & 6998.00 & .67 & 7305.00 & .30 \\
\hline Sometimes I find myself thinking about times when the beach was larger & 4198.00 & $<.01$ & 6583.00 & .24 & 7644.00 & .71 \\
\hline I feel that the beach suited my way of life more in the past & 5142.50 & $<.01$ & 7149.00 & .91 & 7527.00 & .55 \\
\hline I am upset over the loss of the beach because it is part of my heritage & 4095.50 & $<.01$ & 7119.00 & .87 & 7557.00 & .59 \\
\hline Place attachment & 4219.00 & $<.01$ & 5837.50 & .18 & 6259.50 & .10 \\
\hline I have good memories of Courtown beach & 5094.50 & $<.01$ & 5879.00 & .15 & 7046.50 & .84 \\
\hline I feel part of the community in Courtown & 5288.50 & $<.01$ & 6749.50 & .21 & 7690.00 & .62 \\
\hline Courtown beach is part of my identity & 4953.00 & $<.01$ & 5816.00 & .15 & 6521.50 & .24 \\
\hline Development of the area is important to me & 4862.50 & $<.01$ & 5665.50 & .04 & 6588.00 & .22 \\
\hline No other place can compare to Courtown beach & 5531.00 & $<.01$ & 6508.00 & .97 & 6512.50 & .23 \\
\hline I get more satisfaction out of visiting Courtown beach than any other & 5472.50 & $<.01$ & 6137.00 & .43 & 6283.50 & .11 \\
\hline
\end{tabular}

into three groups representing high $(M=2.39)$, medium $(M=$ 2.67) and low $(M=3.00)$ levels of place attachment. The results from the Kruskal-Wallis test indicate statistically significant differences between levels of place attachment and strength of solastalgia using our uni-dimensional scale $(H=$ $64.49, p<.01$ ), with a mean rank of 84.50 for high, 127.98 for medium and 176.53 for low levels of place attachment. Similar statistically significant results were found for all place attachment scale items. Results indicate that people with high levels of place attachment tend to experience stronger feelings of solastalgia (see Fig. 2c).

\section{Association between solastalgia, place attachment and outlook for the future}

Respondents tended to strongly agree with the statement ' $I$ am concerned that future generations will not be able to enjoy the natural environment at Courtown' $(M=1.52, \mathrm{SD}=0.77)$ (Table 2). However, when asked about their own future, responses were more uncertain, with most neither agreeing nor disagreeing with the statement 'there is not much of a future for me in Courtown' $(M=3.34$, SD = 1.22). Indeed, respondents were somewhat optimistic when responding to the statement 'I feel that Courtown has a positive future' $(M=2.51$, $\mathrm{SD}=1.10$ ).

Significant positive correlations are found between solastalgia and single-item statements measuring a pessimistic outlook for the future, including 'there is not much of a future for me in Courtown' (rho $=0.36, n=264, p<0.01$ ) and 'I am concerned that future generations will not be able to enjoy the natural environment at Courtown' (rho $=0.60, n=266, p<$ $0.01)$. Solastalgia has a stronger relationship with the resident's feelings of concern for future generations and personal future outlook than place attachment (see Table 5). However, place attachment shows a stronger positive relationship with 'I feel that Courtown has a positive future' and may be linked to more positive place emotions.

\section{Discussion}

We explored how solastalgia caused by environmental change is currently being experienced by a community in the southeast of Ireland. We investigated relationships between solastalgia, place attachment and place disruption, together with the association between solastalgia, place attachment and outlook for the future. Solastalgia resulting from loss of place is experienced by a large proportion of residents. Fortytwo percent of respondents indicated their lives had been negatively impacted by loss of the beach through impacts on recreation, meeting family, views/aesthetics, community, tourism, memories and therapeutic opportunities. Our results show that solastalgia in Courtown/Riverchapel is being expressed most strongly though feelings of sadness, worry and disappointment. This is consistent with the findings of McNamara and Westoby (2011) who also indicate the importance of these emotions in the experience of solastalgia. We found length of residence to be the demographic variable most 


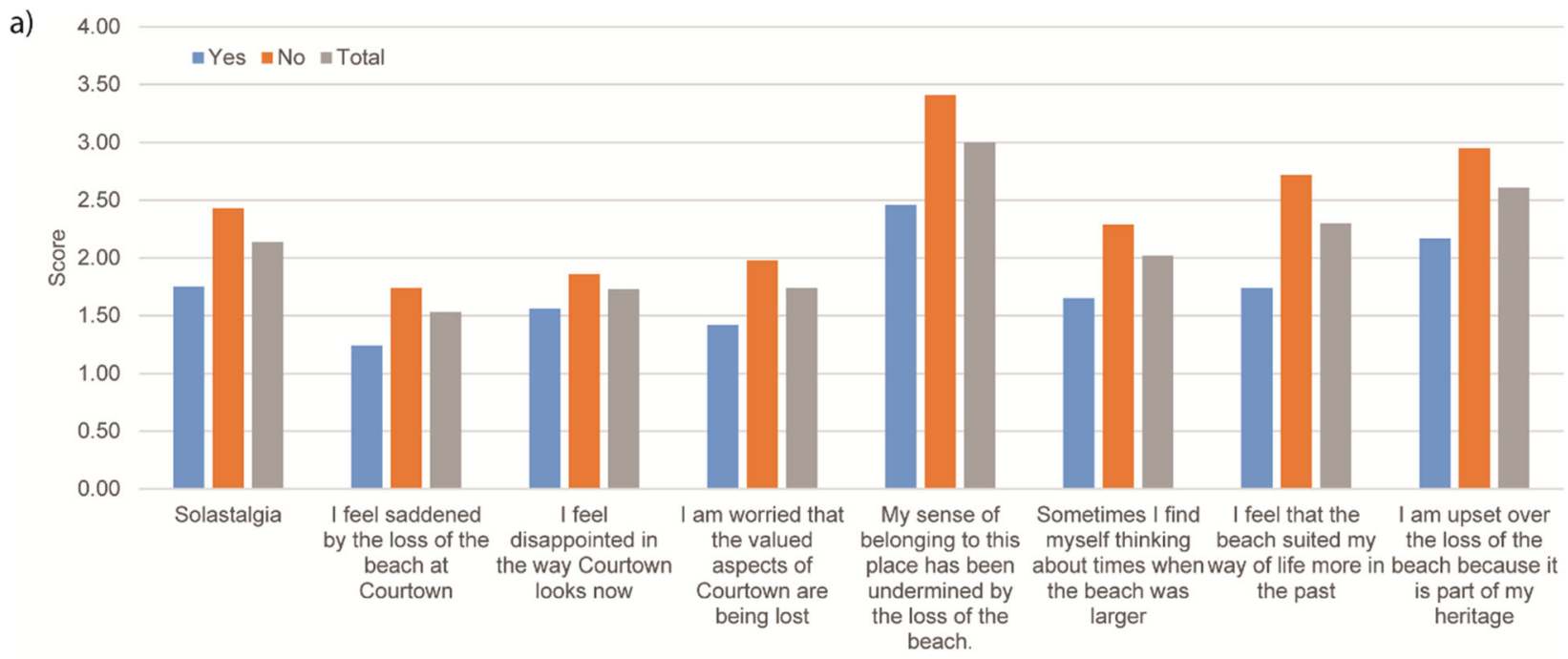

b)
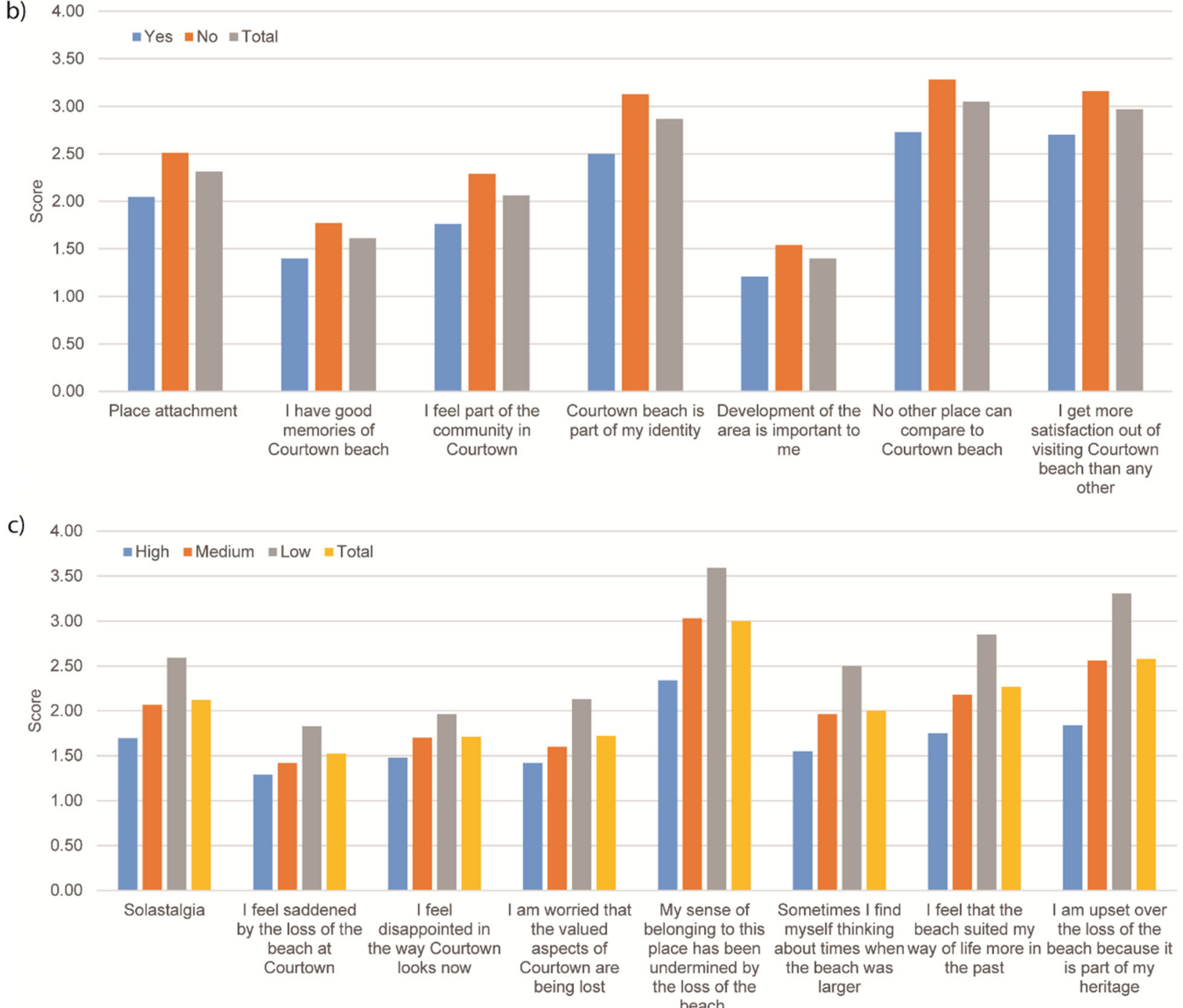

Fig. 2 a Strength of solastalgia (single composite item and scale items, see Table 2) for residents impacted (yes), not impacted (no) and total sample. b Strength of place attachment (single composite item and scale items, see Table 2) for residents impacted, not impacted and total sample. c Strength of solastalgia (single composite item and scale items, see
Table 2) by level of place attachment (high, medium, low). The 5-point Likert scale responses range from $1=$ Strongly agree, $2=$ Agree, $3=$ Neither agree nor disagree, $4=$ Disagree, $5=$ Strongly disagree. Lower scores indicate a stronger sentiment 
strongly correlated with solastalgia. In particular, we found that those living in the area more than 20 years expressed the strongest levels of solastalgia in our sample.

Given our sampling of residents across winter and summer periods, we were able to explore seasonal variations in the experience of solastalgia. Notably, we found that those experiencing the highest levels of solastalgia show evidence of seasonal differences in expression, with negative emotions being stronger in summer. This makes sense given the beach and associated tourism is also strongly seasonal with loss and its impact likely to be most acute in summer months. Unlike the study of McNamara and Westoby (2011) on Australia's Erub Island, we did not find a gendered aspect to the experience of solastalgia. However, McNamara and Westoby (2011) did highlight uncertainty in whether experiences of solastalgia expressed in their study were more strongly due to gender or participants being elders.

We used survey items representing solastalgia tailored from the environmental distress scale developed by Higginbotham et al. (2006). Our findings indicate the utility of these measures given the strong internal reliability of our solastalgia scale, together with the close coherence between the experience of solastalgia and respondents that indicated their lives were impacted by loss of the beach. Our findings therefore support the deployment of these measures in other settings.

In line with previous research, we found a significant positive correlation between solastalgia and place attachment, despite using different measures of place attachment (Higginbotham et al. 2006; Eisenman et al. 2015; Albrecht 2007). Higginbotham et al. (2006) stated that higher place attachment results in more intense feelings of solastalgia following disruption; our results concur. Despite extensive and ongoing place disruption, residents of Courtown and Riverchapel still show moderate levels of place attachment. Like solastalgia, we found that place attachment increases with length of residence. Notably, when considering the dependence and identity components of place attachment, we found place dependence to have a weaker expression than place identity. This may reflect adaptation among residents in their relationship with place. While some of our respondents indicate how they have adapted to the loss of the beach by undertaking recreational and other activities elsewhere, including other beaches and nearby forests, we do not have sufficient data to assess if place dependence has significantly shifted as the beach has disappeared. Such hypotheses will be further explored using in-depth interviews with residents in future research.

We found interesting differences in the relationships of solastalgia and place attachment with outlook for the future. Connor et al. (2004) highlight the link between solastalgia and concern for the future. We also found that solastalgia is positively correlated with a more pessimistic outlook, both for respondents themselves and for future generations. However, place attachment, even for those experiencing solastalgia, has a positive correlation with more optimistic outlooks and the statement that Courtown has a positive future. Previous studies have indicated that when highly attached individuals experience loss of place, solastalgia can lead to increased engagement in place protective behaviours (Higginbotham et al. 2006; Eisenman et al. 2015; Albrecht 2007; Lemée et al. 2019). Follow-up work through in-depth interviews will further unpack this finding.

Despite positive outlooks associated with place attachment, ongoing negative changes to our case study location will likely intensify with inevitable sea level rise and possible changes in storminess associated with climate change (Pachauri et al. 2014). Therefore, it is likely that experiences of solastalgia will become a more dominant part of resident's everyday lived experience of place. Disruption of people-place relations and associated impacts on well-being have a long history of study; however, grief from place loss is rarely included (Cunsolo and Ellis 2018), while recent research shows that solastalgia can been linked to mental health problems (Rehling and Sigston 2020). Solastalgia and place change is not only an issue related to landscape icons. We have shown that solastalgia is experienced by local communities due to more mundane, chronic and slowly unfolding issues such as coastal erosion
Table 5 Bivariate correlations between solastalgia (one composite item, see Table 2), place attachment (one composite item, see Table 2), sociodemographics (age, length of residence) and statements concerning future outlook from the annual sample. The 5-point Likert scale responses range from $1=$ Strongly agree, 2 = Agree, $3=$ Neither agree nor disagree, $4=$ Disagree, $5=$ Strongly disagree

\begin{tabular}{lll}
\hline Scales and items & Place attachment & Solastalgia \\
\hline Place attachment (One single composite item) $n=265$ & & $.49^{* *}$ \\
Future outlook Likert statements & & $.60^{* *}$ \\
I am concerned that future generations will not be able to enjoy & $.34^{* *}$ & $.36^{* *}$ \\
$\quad$ the natural environment at Courtown & .1 & -.03 \\
There is not much of a future for me in Courtown & $.20^{* *}$ & $.19^{* *}$ \\
I feel that Courtown has a positive future & .04 & $.25^{* *}$ \\
Age & $.19^{* *}$ & \\
\hline
\end{tabular}

**Significant at the 0.01 level 
(Marshall et al. 2019; Connor et al. 2004). Given the widespread experience of such change worldwide, together with exposure to sea level rise with climate change, it is important to further understand the impacts of solastalgia and potential interactions with place attachment in different contexts.

Finally, we note some limitations. Critiques of quantitative approaches suggest that complex concepts such as place attachment and solastalgia cannot be explored in depth with empirical measures. However, many scholars have attempted to quantify such concepts at community level and achieved meaningful results (Clarke et al. 2018; Kaltenborn and Bjerke 2002; Higginbotham et al. 2006). The results of all surveys are sensitive to the way in which questions are asked, with correct language usage important to avoid biased wording which can promote a particular perspective (Salant and Dillman 1994). To avoid this issue, we spent time in the community talking with residents about the beach and listening to how they described changes to their environment to help formulate our survey. Use of our survey beyond this case study should be sensitive to the language used and calibrate questions to local context.

\section{Conclusion}

Place loss has profound impacts on individual and community well-being and can influence ability to cope with further environmental change (Fresque-Baxter and Armitage 2012). Using the gradual disappearance of a beach in Courtown/ Riverchapel, Ireland as a case study, we analysed survey results to assess links between the impacts of slow and ongoing place loss, place attachment, solastalgia and outlook for the future in a coastal community. We find ample evidence for the experience of solastalgia in the community, with emotions of sadness, worry and disappointment most strongly expressed. Solastalgia was most strongly correlated with length of residence in the community and expression strongest for those who have lived in Courtown/Riverchapel for more than 20 years. We found place attachment and the experience of solastalgia to be strongly positively correlated. Place attachment was most weakly expressed through place dependence, suggesting ongoing adaptation of relationships with place in the community. Moreover, solastalgia was strongly correlated with a negative outlook for the future, both for individuals and future generations. Residents who experienced the highest levels of solastalgia also show seasonal differences in expression, with solastalgia being strongest in summer, when impacts from loss of the beach are likely most acute. Our findings demonstrate the complexity of emotional responses to environmental loss and indicate that more in-depth qualitative methods may be needed to parse these complexities. Our approach and findings are also likely to be of interest beyond our case study. Place disruption due to slow, creeping coastal erosion is widely experienced globally. Inevitable sea level rise and enhanced coastal erosion associated with anthropogenic climate change means that understanding and addressing solastalgia will be critical to underpin successful adaptation.

Supplementary Information The online version contains supplementary material available at https://doi.org/10.1007/s10113-021-01778-y.

Acknowledgements We thank the residents of Courtown Harbour and Riverchapel for participating in this study and Eugene Doyle, Patrick Comerford and Tomasz Bialecki for contributing and editing images. We thank Patrick Bresnihan and Sam Grainger for useful discussion on earlier drafts. We also thank the Editor and two anonymous reviewers whose insightful comments helped improve our paper.

Funding Open Access funding provided by the IReL Consortium. This study was co-funded by the Irish Research Council and Environmental Protection Agency, project ID GOIPG/2019/1657.

Open Access This article is licensed under a Creative Commons Attribution 4.0 International License, which permits use, sharing, adaptation, distribution and reproduction in any medium or format, as long as you give appropriate credit to the original author(s) and the source, provide a link to the Creative Commons licence, and indicate if changes were made. The images or other third party material in this article are included in the article's Creative Commons licence, unless indicated otherwise in a credit line to the material. If material is not included in the article's Creative Commons licence and your intended use is not permitted by statutory regulation or exceeds the permitted use, you will need to obtain permission directly from the copyright holder. To view a copy of this licence, visit http://creativecommons.org/licenses/by/4.0/.

\section{References}

Adger WN, Butler C, Walker-Springett K (2017) Moral reasoning in adaptation to climate change. Environ Polit 26(3):371-390. https:// doi.org/10.1080/09644016.2017.1287624

Albrecht G (2005) 'Solastalgia': a new concept in health and identity. Philos Activism Nat 3:41-55 https://search.informit.org/doi/10. 3316/informit.897723015186456

Albrecht G (2006) Environmental distress as solastalgia. Alternatives 32(4/5):34-35

Albrecht GA (2019) Earth emotions: new words for a new world. Cornell University Press, New York

Albrecht G, Sartore GM, Connor L, Higginbotham N, Freeman S, Kelly B, Stain H, Tonna A, and Pollard G (2007) Solastalgia: the distress caused by environmental change. Australasian Psychiatry 15(sup1): S95-S98. https://doi.org/10.1080/10398560701701288

Allred SB, Ross-Davis A (2011) The drop-off and pick-up method: an approach to reduce nonresponse bias in natural resource surveys. Small-Scale Forestry 10(3):305-318. https://doi.org/10.1007/ s11842-010-9150-y

Anton CE, Lawrence C (2016a) Does place attachment predict wildfire mitigation and preparedness? A comparison of wildland-urban interface and rural communities. Environ Manag 57(1):148-162. https://doi.org/10.1007/s00267-015-0597-7 
Anton CE, Lawrence C (2016b) The relationship between place attachments, the theory of planned behaviour and residents' response to place change. J Environ Psychol 47:145-154. https://doi.org/10. 1016/j.jenvp.2016.05.010

Askland HH, Bunn M (2018) Lived experiences of environmental change: solastalgia, power and place. Emot Sp Soc 27:16-22. https://doi.org/10.1016/j.emospa.2018.02.003

Barnett J, Tschakert P, Head L, Adger WN (2016) A science of loss. Nat Clim Change 6(11):976. https://doi.org/10.1038/nclimate3140

Belanche D, Casaló LV, Flavián C (2017) Understanding the cognitive, affective and evaluative components of social urban identity: determinants, measurement, and practical consequences. J Environ Psychol 50:138-153. https://doi.org/10.1016/j.jenvp.2017.02.004

Cheng CK, Chou SF (2015) The influence of place change on place bonding: a longitudinal panel study of renovated park users. Leisure Sci 37(5):391-414. https://doi.org/10.1080/01490400. 2015.1021883

Clarke D, Murphy C, Lorenzoni I (2018) Place attachment, disruption and transformative adaptation. J Environ Psychol 55:81-89. https:// doi.org/10.1016/j.jenvp.2017.12.006

Clayton S, Karazsia BT (2020) Development and validation of a measure of climate change anxiety. J Environ Psychol 69:101434. https://doi. org/10.1016/j.jenvp.2020.101434

Connor L, Albrecht G, Higginbotham N, Freeman S, Smith W (2004) Environmental change and human health in Upper Hunter communities of New South Wales, Australia. EcoHealth 1(2):SU47-SU58. https://doi.org/10.1007/s10393-004-0053-2

CSO Census (2011) County Wexford (CSO Area Code CTY 14). CSO. https://census.cso.ie/sapmap2011/Results.aspx?Geog Type= CTY\&Geog_Code $=14 \&$ CTY=01. Accessed 03 September 2019.

CSO Census (2016) Sapmap area: settlements Courtown HarbourRiverchapel-Ardamine. CSO. http://census.cso.ie/sapmap2016/ Results.aspx?Geog_Type=ST2016\&Geog_Code=BEC95FD094C0-4DB2-8290-04BDCFC073C3. Accessed 03 Sept 2019

Cunsolo A, Ellis NR (2018) Ecological grief as a mental health response to climate change-related loss. Nat Clim Change 8(4):275. https:// doi.org/10.1038/s41558-018-0092-2

Devine-Wright P (2009) Rethinking NIMBYism: the role of place attachment and place identity in explaining place-protective action. $\mathrm{J}$ Community Appl Soc Psychol 19(6):426-441. https://doi.org/10. 1002/casp.1004

Devine-Wright P (2013) Think global, act local? The relevance of place attachments and place identities in a climate changed world. Glob Environ Change 23(1):61-69. https://doi.org/10.1016/j.gloenvcha. 2012.08.003

Devine-Wright P, Howes Y (2010) Disruption to place attachment and the protection of restorative environments: a wind energy case study. J Environ Psychol 30(3):271-280. https://doi.org/10.1016/j.jenvp. 2010.01.008

Eisenman D, McCaffrey S, Donatello I, Marshal G (2015) An ecosystems and vulnerable population's perspective on solastalgia and psychological distress after a wildfire. EcoHealth 12(4):602-610. https:// doi.org/10.1007/s10393-015-1052-1

Ellis NR, Albrecht GA (2017) Climate change threats to family farmers' sense of place and mental wellbeing: a case study from the Western Australian Wheat belt. Soc Sci Med 175:161-168. https://doi.org/ 10.1016/j.socscimed.2017.01.009

Fresque-Baxter JA, Armitage D (2012) Place identity and climate change adaptation: a synthesis and framework for understanding. Wiley Interdisciplinary Reviews: Climate Change 3(3):251-266. https:// doi.org/10.1002/wcc.164

Fried M (2000) Continuities and discontinuities of place. J Environ Psychol 20(3):193-205. https://doi.org/10.1006/jevp.1999.0154

Fullilove MT (1996) Psychiatric implications of displacement: contributions from the psychology of place. American J Psychiatry 153(12): 1516-1523. https://doi.org/10.1176/ajp.153.12.1516
Galway LP, Beery T, Jones-Casey K, Tasala K (2019) Mapping the solastalgia literature: a scoping review study. International Journal of Environmental Research and Public Health 16(15):2662. https:// doi.org/10.3390/ijerph16152662

Gorey Guardian (2019) Courtown beach project 'unlikely to proceed for number of years'. Gorey Guardian. https://www.independent.ie/ regionals/goreyguardian/news/courtown-beach-project-unlikely-toproceed-for-number-of-years-38526862.html. Accessed 20 April 2020

Greer A, Binder SB, Thiel A, Jamali M, Nejat A (2020) Place attachment in disaster studies: measurement and the case of the 2013 Moore tornado. Popul Environ 41(3):306-329. https://doi.org/10.1007/ s11111-019-00332-7

Hess JJ, Malilay JN, Parkinson AJ (2008) Climate change: the importance of place. American Journal of Preventive Medicine 35(5):468 478. https://doi.org/10.1016/j.amepre.2008.08.024

Higginbotham N, Connor L, Albrecht G, Freeman S, Agho K (2006) Validation of an environmental distress scale. EcoHealth 3(4): 245-254. https://doi.org/10.1007/s10393-006-0069-x

Kaltenborn BP, Bjerke T (2002) Associations between landscape preferences and place attachment: a study in Røros, Southern Norway. Landsc Res 27(4):381-396. https://doi.org/10.1080/ 0142639022000023943

Korpela KM (1989) Place-identity as a product of environmental selfregulation. J Environ Psychol 9(3):241-256. https://doi.org/10. 1016/S0272-4944(89)80038-6

Lemée C, Fleury-Bahi G, Navarro O (2019) Impact of place identity, selfefficacy and anxiety state on the relationship between coastal flooding risk perception and the willingness to cope. Frontiers in Psychology 10:499. https://doi.org/10.3389/fpsyg.2019.00499

Lewicka M (2011) Place attachment: how far have we come in the last 40 years? J Environ Psychol 31(3):207-230. https://doi.org/10.1016/j. jenvp.2010.10.001

Marshall N, Adger WN, Benham C, Brown K, Curnock MI et al (2019) Reef grief: investigating the relationship between place meanings and place change on the Great Barrier Reef, Australia. Sustainability Sci:1-9. https://doi.org/10.1007/s11625-019-00666-Z

McKnight ML, Sanders SR, Gibbs BG, Brown RB (2017) Communities of place? New evidence for the role of distance and population size in community attachment. Rural Sociology 82(2):291-317. https:// doi.org/10.1111/ruso.12123

McNamara KE, Westoby R (2011) Solastalgia and the gendered nature of climate change: an example from Erub Island, Torres Strait. EcoHealth 8(2):233-236. https://doi.org/10.1007/s10393-0110698-6

Moore RL, Graefe AR (1994) Attachments to recreation settings: the case of rail-trail users. Leisure Sci 16(1):17-31. https://doi.org/10.1080/ 01490409409513214

Ojala M (2013) Coping with climate change among adolescents: implications for subjective well-being and environmental engagement. Sustainability 5(5):2191-2209. https://doi.org/10.3390/su5052191

Pachauri RK, Allen MR, Barros VR, Broome J, Cramer W et al (2014) Climate change 2014: synthesis report: Contribution of Working Groups I, II and III to the fifth assessment report of the Intergovernmental Panel on Climate Change. IPCC, Geneva

Pallant J (2013) SPSS survival manual. A step by step guide to data analysis using IBM SPSS, 5th edn. Open University Press, Berkshire

Proshansky HM, Fabian AK, Kaminoff R (1983) Place-identity: physical world socialization of the self. J Environ Psychol 3(1):57-83. https://doi.org/10.1016/S0272-4944(83)80021-8

Quinn T, Lorenzoni I, Adger WN (2015) Place attachment, identity, and adaptation. In: O'Brien KL, Selboe E (eds) The adaptive challenge of climate change. Cambridge University Press, New York, pp 160 170. https://doi.org/10.1017/CBO9781139149389.010 
Rehling J, Sigston E (2020) Disrupted attachments to cherished places: global experiences of 'solastalgia' and their clinical implications. Clinical Psychol Forum 332:35-39

Ruiz C, Hernández B (2014) Emotions and coping strategies during an episode of volcanic activity and their relations to place attachment. J Environ Psychol 38:279-287. https://doi.org/10.1016/j.jenvp.2014. 03.008

Salant P, Dillman DA (1994) How to conduct your own survey. John Wiley and sons, New York

Stokols D, Shumaker SA (1987) People in place: a transactional view of settings. In: Yadav CS (ed) Perceptual and cognitive image of the city, 1st edn. Concept publishing company, New Deli, pp 441-488

Tran J, Divine LM, Heffner LR (2020) "What are you going to do, Protest the Wind?": community perceptions of emergent and worsening coastal erosion from the remote Bering sea community of St. Paul. Alaska. Environ Manag:1-24. https://doi.org/10.1007/s00267-02001382-6

Twigger-Ross CL, Uzzell DL (1996) Place and identity processes. J Environ Psychol 16(3):205-220. https://doi.org/10.1006/jevp. 1996.0017

Von Wirth T, Grêt-Regamey A, Moser C, Stauffacher M (2016) Exploring the influence of perceived urban change on residents' place attachment. J Environ Psychol 46:67-82. https://doi.org/10. 1016/j.jenvp.2016.03.001

Warsini S, Buettner P, Mills J, West C, Usher K (2014) Translation, cultural adaptation, and psychometric testing of the environmental distress scale with Indonesian survivors of a volcanic eruption.
Disaster Medicine and Public Health Preparedness 8(3):229-238. https://doi.org/10.1017/dmp.2014.45

WCC (2014a) Courtown and Riverchapel Local Area Plan 2015-2021. Wexford County Council https://www.wexfordcoco.ie/sites/default/ files/content/Planning/CourtownRiverchapelLAP15-21/ Appendix2-AppropriateAssessmentScreeningReport.pdf. Accessed 27 Aug 2019

WCC (2014b) Courtown and Riverchapel Local Area Plan 2015-2021, Appendix 1 Strategic Environmental Assessment Screening Report. Wexford County Council. https://www.wexfordcoco.ie/sites/ default/files/content/Planning/CourtownRiverchapelLAP15-21/ Appendix 1-SEAScreeningReport.pdf. Accessed 27 Aug 2019

WCC (2018) Socio-Economic Profile 1: Employment, Industry \& Occupation. WCC. https:/www.wexfordcoco.ie/sites/default/files/ content/Planning/Profile-1-Employment-Industry-Occupation.pdf. Accessed 13 Sept 2019

WCC (2019) Public Consultation - Courtown North Beach and Marina Feasibility Study. Wexford County Council. https://www. wexfordcoco.ie/council-and-democracy/public-consultations. Accessed 20 April 2020

Williams DR, Vaske JJ (2003) The measurement of place attachment: validity and generalizability of a psychometric approach. Forest Sci 49(6):830-840. https://doi.org/10.1093/forestscience/49.6.830

Publisher's note Springer Nature remains neutral with regard to jurisdictional claims in published maps and institutional affiliations. 